\title{
The effect of New Zealand blackcurrant on sport performance and related biomarkers: a systematic review and meta-analysis
}

\author{
A. J. Braakhuis ${ }^{1 *}$ (D, V. X. Somerville ${ }^{1}$ and R. D. Hurst $^{2}$
}

\begin{abstract}
Background: Blackcurrants have come to be regarded as a superfood because of their high polyphenol content, namely anthocyanins. While many berry types have been studied, blackcurrant-anthocyanins may be the superior berry when it comes to athletic performance. The purpose of the review was to evaluate the effects of blackcurrant supplementation on athletic performance, oxidative markers, cognition, and side effects.

Methods: Systematic review and meta-analysis. Review manager software (version 5.3) was used for the meta-analysis. The risks of bias was independently assessed using the guidelines and criteria outlined in the Cochrane Handbook for Systematic Reviews of Interventions. The data sources for the search included MEDLINE (Ovid), Google Scholar databases, additional references lists, conference proceedings and grey literature until August 2019. Eligibility Criteria included all blackcurrant (New Zealand derived) interventions, randomised control trials, human participants, placebo-controlled only.

Results: A total of 16 separate studies met the criteria for inclusion in the systematic review, with 9 studies contributing to this sport performance meta-analysis. There was an improvement in sport performance when supplementing with blackcurrant, 0.45 (95\% Cl 0.09-0.81, $p=0.01$ ). The effective dose appears to be between 105 and $210 \mathrm{mg}$ of total blackcurrant anthocyanins, prior to exercise. There were insufficient studies reporting oxidative markers, cognitive effects or biomarkers, and/or side effects to comment on the mechanism of action.
\end{abstract}

Conclusion: Blackcurrant has a small, but significant, effect on sport performance, with no known detrimental side effects.

Keywords: Anthocyanin, Berry, Exercise, Athlete

\section{Introduction}

The popularity of perceived naturally occurring plant extracts and phytochemicals to enhance physical performance, exercise recovery and maintain health has increased dramatically in recent years. Interest in the health properties and benefits of blackcurrants for active individuals started over 10 years ago $[1,2]$; however the last 5 years has seen a surge in research interest [3]. In 2018, the International Olympic Committee (IOC) released a statement on the efficacy of dietary

\footnotetext{
* Correspondence: a.braakhuis@auckland.ac.nz

1 Discipline of Nutrition, Faculty of Medical \& Health Sciences, The University of Auckland, Private Bag, Auckland 92019, New Zealand

Full list of author information is available at the end of the article
}

supplements for athletes, in which polyphenols were reported to increase mitochondrial biogenesis and endurance performance, at least in mice [4]. The IOC highlighted the importance of conducting reviews using a systematic process and in their hierarchy of scientific evidence, systematic reviews and the process of meta-analysis were considered the gold standard [4]. A semi-recent systematic review and meta-analysis investigated the effect of polyphenols, albeit a very broad dietary group, on athletic performance in humans [5] and demonstrated a significant improvement when taking polyphenols for 7 days or more. Given the review included all polyphenols and accepting the broad nature of the inclusion criteria, translating this finding into a recommendation

(c) The Author(s). 2020 Open Access This article is licensed under a Creative Commons Attribution 4.0 International License, which permits use, sharing, adaptation, distribution and reproduction in any medium or format, as long as you give appropriate credit to the original author(s) and the source, provide a link to the Creative Commons licence, and indicate if changes were made. The images or other third party material in this article are included in the article's Creative Commons licence, unless indicated otherwise in a credit line to the material. If material is not included in the article's Creative Commons licence and your intended use is not permitted by statutory regulation or exceeds the permitted use, you will need to obtain permission directly from the copyright holder. To view a copy of this licence, visit http://creativecommons.org/licenses/by/4.0/ The Creative Commons Public Domain Dedication waiver (http://creativecommons.org/publicdomain/zero/1.0/) applies to the data made available in this article, unless otherwise stated in a credit line to the data. 
for athletes is problematic. In the current review we investigate blackcurrants (Ribes nigrum), which are naturally high in a particular range of polyphenols and may provide an opportunity to be specific regarding optimal dosing strategies.

Berries are a brightly coloured fruit which have been investigated for their health-promoting effects, particularly blackcurrant, blueberries (Vaccinium spp), and blackberry (Rubus spp). Berries contain high concentrations of a particular class of flavonoids called anthocyanins, but each berry type has a specific make-up of anthocyanins $[3,6]$. Anthocyanins are natural pigments responsible for the blue, purple, red and orange colours of many fruits and vegetables [6]. While the total daily consumption of total anthocyanins has been estimated to be between 3 and $215 \mathrm{mg} /$ day [6], the optimal intake of total and specific anthocyanins is uncertain. In general, blackcurrant contains between 130 and $460 \mathrm{mg} / 100$ $\mathrm{g}$ fruit weight of total anthocyanins [6] and the predominant type is delphinidin-3-rutinoside. In contrast, blueberries contain $62-300 \mathrm{mg} / 100 \mathrm{~g}$ fruit weight of total anthocyanins [6] with the predominant type being malvidin-3-monogalactoside [7]. Blackcurrant anthocyanins have shown to alleviate inflammation and oxidative stress, while preventing the depletion of mitochondrial content and damage [8], not reported with blueberry anthocyanins. Thus blackcurrant anthocyanins (delphinidin glycosides) appear to be a more effective antioxidant than blueberry anthocyanins (malvidin glycosides) [9, 10]. The physiological effects of the different berries suggests not all polyphenols and anthocyanins have the same bioactivity.

While the general health benefit claims of blackcurrants are warranted, there are few studies comparing the anthocyanin content of different blackcurrant varieties grown in a range of countries. New Zealand blackcurrants (NZ BC) have been reported to have higher concentrations of anthocyanins and other phytochemicals than those grown in other countries, which is a likely consequence of an environment with high UV and long, sunny days. The anthocyanin content of juice produced from $\mathrm{NZ} \mathrm{BC}$ has previously been shown to be between 336 and $850 \mathrm{mg} / 100 \mathrm{~mL}$, in comparison to non-NZ blackcurrants with an anthocyanin content ranging from 170 to $310 \mathrm{mg} / 100$ $\mathrm{mL}$ of juice [11]. While acknowledging the total amount of blackcurrant anthocyanins consumed is likely to be a key factor, for pragmatic reasons a concentrated dose might be preferable for athletes, particularly prior to an event. As such, the purpose of the review was to determine whether blackcurrant anthocyanins, particularly from NZ BC, alter direct and indirect aspects of athletic performance. In particular, does NZ BC improve athletic performance and modulate oxidative and cognitive effects?

\section{Main text \\ Methods \\ Search strategy and study selection}

A search strategy was developed using appropriate $\mathrm{MeSH}$ terms and boolean operators, in which the predominant search terms covered blackcurrant, sport, exercise and cognition with limits for randomised control trials and healthy human participants. Interventions were required to be placebo-controlled NZ BC interventions, include a maximal exercise performance test and be written in English. Only studies conducted at sealevel or standard oxygen concentrations were included. The initial strategy was developed prior to the full investigation. An electronic search was conducted for all studies investigating the effects of blackcurrant, derived from New Zealand, on exercise performance via MEDLINE (Ovid) and Google Scholar databases. The MEDLINE search strategy can be located in the Supplementary Data files. Relevant reference lists and conference proceedings follow-up provided valuable unpublished data. The search period was not restricted by year of publication (up to August 15th 2019). The title and abstract of each study were initially screened during the electronic search to exclude irrelevant studies from the database list. Pre-specified inclusion and exclusion criteria were applied to the abstracts of remaining studies. The full texts or abridged report, if sufficient information was provided, were then assessed for eligibility and those that met inclusion criteria were critically appraised and quality checked to reach a final decision. Two authors (AB, VS) carried out the search independently, and then resolved any disagreements.

The primary outcome under investigation was sport performance. Sport performance was defined by a maximal performance test and included clear performance outcomes (typically time to fatigue or timetrial time). Secondary outcomes included inflammatory/oxidative measures (protein carbonyl [PC], malondialdehyde [MDA], ferric reducing ability of plasma [FRAP], Interleukin-1 [IL-1], Interleukin-8 [IL-8], Interleukin-10 [IL-10], Interleukin-6 [IL-6], tumour necrosis factor-alpha [TNF $\alpha]$ ); cognitive function (validated task test, for example: Stroop, Montreal cognitive assessment), monoamine oxidase activity/ concentration (MAO), and any reported side effects. Inclusion criteria specified that the studies must be randomised, placebo-controlled human interventions examining New Zealand blackcurrant. Isolated strength tests and recovery protocols were excluded. Human trials on participants with Parkinson disease were also excluded, as were those without inferential statistics (SE/SD or exact $p$-values), or appropriate methodology (exercise protocol). Ethical committee approval is not required for reviews. 


\section{Risk of bias assessment in included studies}

The risks of bias for all included meta-analysed studies were independently assessed using the guidelines and criteria outlined in the Cochrane Handbook for Systematic Reviews of Interventions [12]. The major sources of bias we chose to assess were random sequence generation (selection bias), allocation concealment (selection bias), blinding (performance bias and detection bias), and selective reporting (reporting bias), as recommended by the Cochrane Handbook [12]. Each study was also checked for bias through the involvement of a conflict of interest by manually checking the acknowledgements and funding source of each study. The risk for each major source of bias was defined as either 'low risk', 'unclear risk', or 'high risk' for each included trial, and a risk of bias table was generated for each meta-analysis.

\section{Data extraction}

The mean, standard deviation and sample size of the sport performance outcomes for intervention and control groups were extracted. Mean performance (time $(\mathrm{min} / \mathrm{sec})$, distance $(\mathrm{m})$ or power (watts)) and variance data were extracted directly from the manuscripts into excel. One study was removed as the data had been reported elsewhere [13]. Data from Willems 2016 [14] was extracted from graphical presentation. Using the Review Manager software a standardised mean performance effect and standard error were calculated for each study. Acknowledging the difficulty with pooling performance data from various exercise test types, we initially conducted the adjustments for tests to exhaustion, exercise and cycle type as described elsewhere [15]. We did however find no difference in using standardised mean difference effects and prior adjustments with mean effects in this data set. Hence, to remove the subjective nature of the manual adjustments, we chose to use the standardised mean difference approach.

Data on the inflammatory and oxidative measures were extracted for at-rest and post-exercise values. If multiple post exercise values were collected, the value closest to immediately post exercise was recorded. Measures provided as a percent change from baseline were excluded as raw or statistically adjusted data were required. In studies of cross-over design that analysed the same participant data in two ways, the most common analysis approach was reported. By way of example, one study reported MDA as protein concentration in the blood, and via the erythrocyte simulation assay [16]. With regards to MDA analysis, protein concentration is the most common method of analysis and thus data reported. In addition, when the same participant data has been collected on acute versus chronic intake, data on chronic intake has been reported here, as this was the most common testing regime. Changes in oxidative stress markers were expressed as ratios (post-exercise measure/pre-exercise measure) for intervention and control. For a marker to be presented graphically there had to be at least three studies with relevant data.

Much of the variance data was presented as mean and SEM. SEM data were converted to standard deviation for standardised reporting in this manuscript. All data sources were considered for inclusion, including abstract information from conference posters, unpublished data and published manuscripts, provided appropriate inferential data could be extracted.

Side effect events were extracted as the total number of episodes over the entire supplementation period, regardless of severity. The reported outcome includes a count score of side effects and description.

\section{Statistical analysis}

Outcomes with equal to or greater than four independent data points were meta-analysed.

Performance data were converted into a percent difference between the intervention and control groups. The variance data between groups was calculated using the mean and standard deviation data from each group and enteredinto the Review Manager (version 5.3, Cochrane, London, UK) calculator to derive the standard error. The mean effect and standard error was used to generate the standardised mean difference. The inverse variance statistical method was chosen to generate the study effect of NZ blackcurrant anthocyanins.

Assessment of heterogeneity between included studies was evaluated by the Higgins score $\left(\mathrm{I}^{2}\right)$. Values of $\mathrm{I}^{2}$ were interpreted using the guidelines outlined in the Cochrane Handbook for Systematic Reviews of Interventions [12], where 0 to $40 \%$ might not be important; 30 to $60 \%$ may represent moderate heterogeneity; 50 to $90 \%$ may represent substantial heterogeneity, and 75 to $100 \%$ may represent considerable heterogeneity [17]. The fixed effects model was adopted when the Higgins score was below $60 \%$; otherwise the random-effects model was used.

To interpret the magnitude of change in the oxidative stress markers, the authors calculated the baseline variability as a $\mathrm{x} / \div$ factor $\mathrm{SD}$, calculated by the equation below. To evaluate the magnitude of change, Cohen's thresholds of $0.20,0.60$, and 1.20 of the factor SD were used, which represents small, moderate, and large respectively.

$$
e \sqrt{\frac{\sum\left(\{\ln ((\text { mean } / \mathrm{SD}) / \text { mean })\}^{2} \cdot d f\right)}{\sum d f}}
$$

\section{Results}

A total of 964 articles were identified through searching databases and other sources. Following removal of 
duplicates, 952 articles remained. After screening by title and abstract, 45 articles remained. Following application of specific inclusion and exclusion criteria, critical appraisal, and quality checking of articles, 16 were deemed acceptable for inclusion. See Fig. 1 PRISMA Chart.

\section{Description of included studies}

Sixteen studies were included in the review. One included sport performance, oxidative stress measures and side effects [16], eight included sport performance data only, [14, 18-24], three had oxidative stress measures [1, $25,26]$, one had oxidative and cognitive measures [27], two included cognitive measures only [28, 29], and one included oxidative measures and side effects [2]. Among the included studies, six were conducted in New Zealand, the remaining in the United Kingdom. Of the nine performance studies with included performance data, all used a cross-over design, and report the effect of New Zealand blackcurrant on either cycling, running or climbing hang time.

\section{Meta-analysis results Blackcurrant and its effect on performance}

The performance effect of NZ BC vs. placebo during exercise was investigated in nine studies. The meta-analysis using the fixed-effects model calculated the standardised mean percent effect of NZ BC on performance to be 0.45 (95\% CI 0.09-0.81, $p=0.01$ ), which is significant. The heterogeneity among studies included in the meta-analysis did not significantly affect the outcome (see Fig. 2).

\section{Risk of bias in included studies}

Whilst there are some gaps in the reported methods of included studies, there is an overall low to unclear risk that the true performance effect of NZ BC has been influenced by bias from included studies. The classification of bias is presented alongside Fig. 2. In summary, the nine studies were all classified as low risk bias for 'random sequence generation' as the cross over design was appropriate and randomisation was conducted. 'Allocation concealment' was unclear as the authors did not state their respective methods. Similarly the nine studies were assigned unclear risk bias of incomplete outcome data' as they were crossover and only included results of participants who had completed both arms of the trial. One study reported drop-out rates with reason, and rated low risk for incomplete data. All studies were classified as low risk of bias for 'blinding' as they were stated double-blind and mentioned intervention and control capsules were identical. A search for the associate protocol of each study was completed, however no protocol was found for all included studies. The studies were therefore all classified as unclear 'selective reporting' bias.
The distinction in 'other' bias classification resulted from inadequate conflict of interest statements. Five studies [14, 16, 19, 20,23] were classified as low 'other' bias as the respective authors specified the study funder had no input in study design, results and/or choice to publish (See Fig. 3). The reviewers classified the remaining studies $[18,21,22,24]$ as unclear or high risk as they provided limited conflict of interest statement regarding trial design and choice to publish by the funder. Industry funded projects were deemed high risk in other sources of bias. Missing data was deemed unclear as data on drop-outs was only available in one study. Other sources of bias include inappropriate wash-out periods which was not detected.

\section{Oxidative stress biomarkers}

Outcomes from MDA and PC conducted during exercise trials were graphed and generally indicate a reduction in oxidative stress under the conditions of exercise. One study did report a greater increase in MDA with the intervention than the control; the other two studies indicating reductions. Both MDA and $\mathrm{PC}$ were raised after exercise with $\mathrm{x} / \div$ factor SDs of 2.58 and 3.36 respectively. The qualitative statement indicating the magnitude of change in the geometric mean were varied between moderate and large; however the overall change in the intervention group was similar to the control group. There were insufficient papers to graphically represent any other oxidative stress or inflammatory markers.

One additional study measured MDA and PC without an exercise trial and reported trivial differences in $\mathrm{PC}$ when taking NZ BC (PC, BC 0.2 vs $\mathrm{PL} 0.18 \mathrm{nmol} / \mathrm{mg}$ protein, at baseline; $B C 0.13 \mathrm{vs} 0.11 \mathrm{nmol} / \mathrm{mg}$ protein, after 12 weeks supplementation), and lower MDA when taking NZ BC (MDA, BC 17.3 vs PL $23.5 \mathrm{ng} / \mathrm{mL}$, at baseline; BC $7 \mathrm{vs}$ PL $10 \mathrm{ng} / \mathrm{mL}$ after 12 weeks supplementation) [1].

Outcome measures have been reported for TNF $\alpha$, IL6, IL-10 and FRAP pre and post-exercise in those taking NZ BC or placebo $[25,26]$. The pre-exercise inflammatory markers were higher with the intervention treatment than placebo (TNFo, BC 3 vs PL $2.1 \mathrm{pg} / \mathrm{mL}$; IL-6, BC 12 vs $10 \mathrm{pg} / \mathrm{mL}$ and IL-10, BC 80 vs $60 \mathrm{pg} / \mathrm{mL}$ ) and oxidative stress marker higher on the intervention than placebo (FRAP, BC 0.15 vs $0.14 \%$ ), although none of these reached significance. The post-exercise inflammatory markers were the same or lower with the intervention treatment than placebo (TNFo, BC 9 vs PL $10 \mathrm{pg}$ / $\mathrm{mL}$; IL-6, BC 20 vs $21 \mathrm{pg} / \mathrm{mL}$ and IL-10, BC 60 vs $60 \mathrm{pg} /$ $\mathrm{mL}$ ) and oxidative stress lower on the intervention than placebo post exercise (FRAP, BC 0.12 vs PL $0.13 \%$ ).

\section{Cognitive biomarkers and effects of blackcurrant}

Three studies reported platelet MAO-B concentrations after consuming $\mathrm{NZ} \mathrm{BC}$ or placebo. All three show clear 


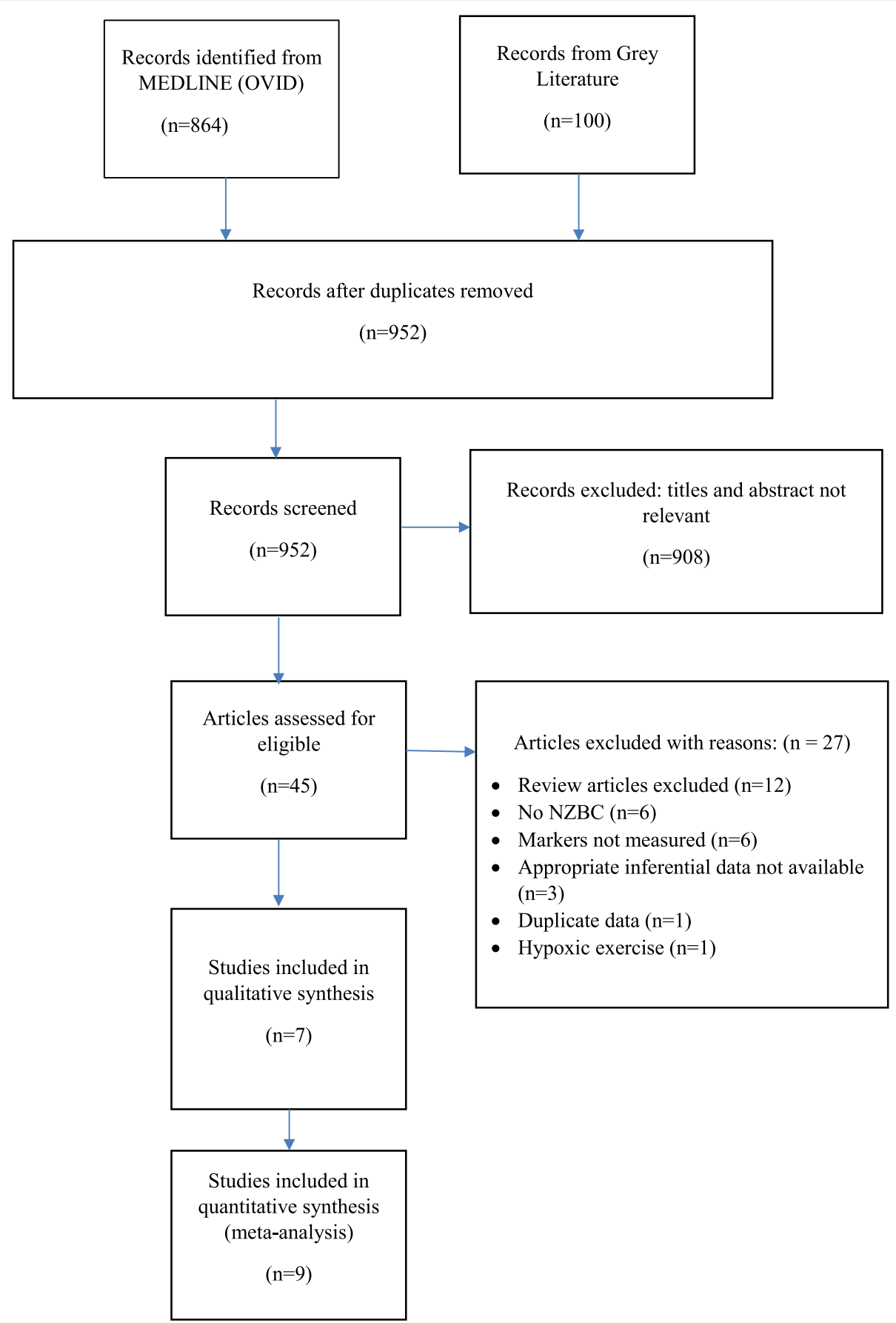

Fig. 1 PRISMA chart outlining identification of included studies

reduction with NZ BC (Platelet MAO-B, BC 1.6 vs PL 22.1 $\mathrm{nM} \mathrm{H} \mathrm{H}_{2} \mathrm{O}_{2}$ production/ $\mu \mathrm{g}$ protein/min [27]; Platelet MAO$\mathrm{B}, \mathrm{BC}-280$ vs PL $10 \mathrm{nmol} \mathrm{H}_{2} \mathrm{O}_{2}$ change from baseline [28]; Platelet MAO-B, BC 1417.86 vs PL $1739.99 \mathrm{nmol} \mathrm{H}_{2} \mathrm{O}_{2}$ [29]). Data were reported using heterogeneous methods thus making graphing or meta-analysis problematic.
Cognitive questionnaire data were reported by one study [28] with a Stroop cognitive test accuracy $(\mathrm{F}=$ $0.014, p>0.01)$ and reaction time $(\mathrm{F}=0.33, p>0.1)$ no better with NZ BC. However, Rapid Visual Information Processing accuracy improved $(\mathrm{F}=5.88, p=0.005)$ with NZ BC. 


\begin{tabular}{|c|c|c|c|c|c|c|}
\hline \multirow[b]{2}{*}{ Study or Subgroup } & \multirow[b]{2}{*}{ Std. Mean Difference } & \multirow[b]{2}{*}{ SE } & \multirow{2}{*}{ Weight } & \multirow{2}{*}{$\begin{array}{l}\text { Std. Mean Difference } \\
\text { IV, Fixed, } 95 \% \mathrm{Cl}\end{array}$} & \multirow{2}{*}{$\begin{array}{l}\text { Std. Mean Difference } \\
\text { IV, Fixed, } 95 \% \mathrm{Cl}\end{array}$} & Risk of Bias \\
\hline & & & & & & $A B C D E F G$ \\
\hline Braakhuis, 2014 & 0 & 0.78 & $5.5 \%$ & $0.00[-1.53,1.53]$ & ד & ๑?९૯૯?† \\
\hline Cook, 2015 & 0.34 & 0.54 & $11.5 \%$ & $0.34[-0.72,1.40]$ & $f^{-}$ & † ?†૯? ? \\
\hline Godwin, 2017 & 1.8 & 1.9 & $0.9 \%$ & $1.80[-1.92,5.52]$ & & 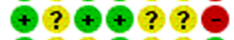 \\
\hline Murphy, 2017 & 0.9 & 3.3 & $0.3 \%$ & $0.90[-5.57,7.37]$ & & ๑? ? †? ? † \\
\hline Perkins, 2015 & 0.52 & 0.5 & $13.4 \%$ & $0.52[-0.46,1.50]$ & $=-$ & ๑ ? † ? ? \\
\hline Perkins, 2019 & 0.3 & 0.5 & $13.4 \%$ & $0.30[-0.68,1.28]$ & - & † ? ?†? ? ? \\
\hline Potter, 2019 & 0.73 & 0.33 & $30.7 \%$ & $0.73[0.08,1.38]$ & - & ??๑๑??† \\
\hline Willems, 2015 & 0.15 & 0.53 & $11.9 \%$ & $0.15[-0.89,1.19]$ & + & ๑ ?†? ? \\
\hline Willems, 2016 & 0.33 & 0.52 & $12.4 \%$ & $0.33[-0.69,1.35]$ & $=$ & $\oplus ? \odot \oplus ? ? \oplus$ \\
\hline Total $(95 \% \mathrm{Cl})$ & & & $100.0 \%$ & $0.45[0.09,0.81]$ & $\checkmark$ & \\
\hline \multicolumn{3}{|c|}{$\begin{array}{l}\text { Heterogeneity: } \mathrm{Chi}^{2}=2.10, \mathrm{df}=8(P=0.98) ;\left.\right|^{2}=0 \% \\
\text { Test for overall effect: } Z=2.47(P=0.01)\end{array}$} & & & $\begin{array}{ccccc}-4 & -1 & 1 & 1 & 1 \\
\text { Favours [control] } & 2 & 4 \\
\text { Favours [nzbc] }\end{array}$ & \\
\hline \multicolumn{7}{|c|}{ Risk of bias legend } \\
\hline \multicolumn{7}{|c|}{ (A) Random sequence generation (selection bias) } \\
\hline \multicolumn{7}{|c|}{ (B) Allocation concealment (selection bias) } \\
\hline \multirow{2}{*}{\multicolumn{7}{|c|}{$\begin{array}{l}\text { (C) Blinding of participants and personnel (performance bias) } \\
\text { (D) Blinding of outcome assessment (detection bias) }\end{array}$}} \\
\hline & & & & & & \\
\hline \multicolumn{7}{|c|}{ (E) Incomplete outcome data (attrition bias) } \\
\hline \multicolumn{7}{|c|}{ (F) Selective reporting (reporting bias) } \\
\hline (G) Other bias & & & & & & \\
\hline \multicolumn{7}{|c|}{$\begin{array}{l}\text { Fig. } 2 \text { Forest plot of performance effects of NZ BC compared to placebo. Results are expressed as standardized mean differences, and } 95 \% \\
\text { confidence intervals (Cl) }\end{array}$} \\
\hline
\end{tabular}

\section{Reported side effects}

Three of sixteen studies made specific mention of reported side effects from taking dietary supplements or drinks containing NZ BC $[2,16,27]$. One reported minor gastrointestinal upset in two of the 24 participants consuming NZ BC [16], which provided the blackcurrant

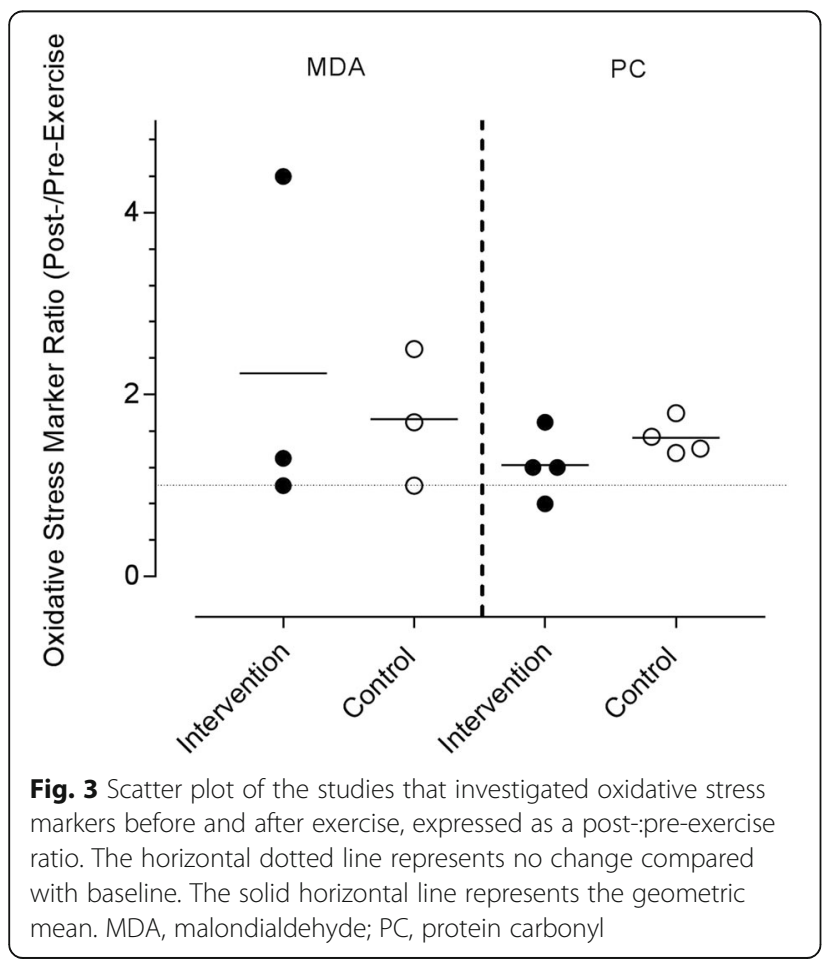

intervention as a drink from a combination of powder extract and concentrated syrup. In two of the studies there were no adverse/ side effects, stomach issues or other consequences from the intervention product [2, 27]. It is worth noting that data on side effects is not systematically collected and reported in all research, we also can't be sure the side effects reported are the direct result of NZ BC or other ingredients or products.

\section{Discussion}

A $1 \%$ difference in athletic performance is relevant to athletes and of sufficient magnitude to affect medal rankings in an Olympic-level competition, with the potential to elevate a medal from fourth to a podium position [30]. The aim of the current review was to systematically evaluate the literature and pool the available evidence to determine the potential benefit of $\mathrm{NZ}$ $\mathrm{BC}$ on athletic performance and whether this is sufficiently relevant to matter. The meta-analysis shows a significant improvement in performance (effect of 0.45) which is quantitatively deemed a small, significant improvement. Interestingly, the magnitude of the effect we report for NZ BC is not dissimilar to caffeine (effect of 0.41 (95\% CI: 0.15-0.68), $p=0.002$ ) [30], which has long been touted as the most potent legal ergogenic food or supplement available.

Whilst acknowledging the majority of the performance research included in the meta-analysis were conducted on sub-elite athletes, one article conducted a subanalysis on participants based on training load [16]. The athletes with higher training loads had a greater 
response to $\mathrm{NZ} \mathrm{BC}$ compared with the low training load group, which might suggest both sub- and elite athletes could benefit.

A recent narrative review highlighted the physiological mechanisms behind the potential of NZ BC [3] stating acute intake may influence cardiovascular alterations such as vasodilation and increased peripheral blood flow, but longer intake durations may be required to result in changes in cellular signaling and mitochondrial adaptations. Of the nine studies included in the performance data, eight used supplement protocols of 7 days, the one remaining study supplemented for 3 weeks, suggesting 7 days is a sufficient length of time to be effective. Alongside the consideration of the ideal anthocyanin supplement length of time is the effective daily dose, which in the performance studies is generally $105-210 \mathrm{mg}$ daily, and in the oxidative and cognitive inclusive studies ranges from 20 to $500 \mathrm{mg}$ daily. One of the performance studies provided participants a daily dose of $300 \mathrm{mg}$ of anthocyanins, and reported minimal performance effects and some minor gastrointestinal side effects, suggesting the ideal dose should be less than $300 \mathrm{mg}$ daily [16]. Recent studies have investigated the dose response of NZ $\mathrm{BC}$, indicating a minimum of $120 \mathrm{mg}$ of blackcurrant anthocyanin taken acutely reduces oxidative stress [25].

The bioavailability of polyphenols and anthocyanins are generally thought to be poorly absorbed with $5-10 \%$ occurring in the small intestine with key metabolites reaching the bloodstream between 0.5 to $1.5 \mathrm{~h}$ after consumption [31], and peak anthocyanin levels reaching the blood stream $2 \mathrm{~h}$ post consumption [25]. As such, the timing of anthocyanin intake to the exercise is a consideration in defining an optimal consumption. Of all included studies, 7 report providing the final dose 2 -h before the relevant testing took place, 2 report 3-h, 4 report $\geq 1$-h, the remaining did not report when the participants consumed the final dose.

The summary of included studies outlined in Table 1 indicate that an NZ BC anthocyanin intake of 105-210 $\mathrm{mg}$ taken for 7 days with the last dose $1-2 \mathrm{~h}$ before activity to be most effective for performance gains. With regards to the management of exercise-induced oxidative stress, data from Table 2 demonstrate effects after a single intake of NZ BC with the minimum dose required of $120 \mathrm{mg}$ of blackcurrant anthocyanins. Further studies are required to determine whether performance benefits are achieved after a single intake.

The NZ BC was provided in various forms which varied between studies, including juice concentrate, powdered juice concentrate, powdered whole fruit and powdered extracted anthocyanins. One study investigated both juice ('BlackAdder' blackcurrant cultivar) and powdered extracted anthocyanins, reporting slightly more anthocyanin content in the powder when made up to an equivalent $200 \mathrm{~mL}$ serve [28]. The improvements in cognition were slightly better with the powdered extract than juice, which also had a lower blood glucose response. The predominant form of NZ BC used in studies was powdered product in capsules to help reduce placebo bias and maintain a consistent anthocyanin content.

To provide insight into the mechanistic action of NZ $\mathrm{BC}$, we investigated the oxidative and inflammatory markers when taking NZ BC. The traditional approach to interpreting oxidative stress and inflammatory markers are to define a reduction as "good", suggesting the underlying oxidative stress and inflammation are

Table 1 Details of blackcurrant studies included in the performance meta-analysis

\begin{tabular}{|c|c|c|c|c|}
\hline Study & Subjects; design & BC anthocyanin dose ${ }^{\mathbf{a}}$ & Final dose & Performance Protocol \\
\hline $\begin{array}{l}\text { Braakhuis, } \\
2014[16]\end{array}$ & $\begin{array}{l}23 \text { females (active); } \\
\text { crossover }\end{array}$ & $\begin{array}{l}300 \mathrm{mg}^{-1} \mathrm{~d}^{-1} \mathrm{BC} \\
\text { anthocyanins for 3-wk }\end{array}$ & $\begin{array}{l}2-3 \mathrm{~h} \\
\text { before test }\end{array}$ & Run time during a $5 \mathrm{~km}$ run time trial (25 min) \\
\hline $\begin{array}{l}\text { Cook, } 2015 \\
{[18]}\end{array}$ & $\begin{array}{l}14 \text { males (active); } \\
\text { crossover }\end{array}$ & $\begin{array}{l}105 \mathrm{mg}^{-1} \mathrm{~d}^{-1} \mathrm{BC} \\
\text { anthocyanins for } 7-\mathrm{d}\end{array}$ & $\begin{array}{l}2 \mathrm{~h} \text { before } \\
\text { test }\end{array}$ & Cycle time during a $16.1 \mathrm{~km}$ cycle time trial ( $28 \mathrm{~min})$ \\
\hline $\begin{array}{l}\text { Godwin, } 2017 \\
{[19]}\end{array}$ & $\begin{array}{l}24 \text { males (active); } \\
\text { crossover }\end{array}$ & $\begin{array}{l}210 \mathrm{mg}^{-1} \mathrm{~d}^{-1} \mathrm{BC} \\
\text { anthocyanins for } 7-\mathrm{d}\end{array}$ & $\begin{array}{l}2 \mathrm{~h} \text { before } \\
\text { test }\end{array}$ & $\begin{array}{l}\text { Sprint time during a repeated run sprint interval test to fatigue } \\
\text { (average of sprint } 3-6,22 \mathrm{~s} \text { ) }\end{array}$ \\
\hline $\begin{array}{l}\text { Murphy, } 2017 \\
{[20]}\end{array}$ & $\begin{array}{l}10 \text { males (active); } \\
\text { crossover }\end{array}$ & $\begin{array}{l}105 \mathrm{mg}^{-1} \mathrm{~d}^{-1} \mathrm{BC} \\
\text { anthocyanins for } 7-\mathrm{d}\end{array}$ & $\begin{array}{l}2 \mathrm{~h} \text { before } \\
\text { test }\end{array}$ & $\begin{array}{l}\text { Cycle time during a twice repeated } 4-\mathrm{km} \text { cycle time trial ( } 12 \\
\text { min) }\end{array}$ \\
\hline $\begin{array}{l}\text { Perkins, } 2015 \\
{[21]}\end{array}$ & $\begin{array}{l}13 \text { males (active); } \\
\text { crossover }\end{array}$ & $\begin{array}{l}105 \mathrm{mg}^{-1} \mathrm{~d}^{-1} \mathrm{BC} \\
\text { anthocyanins for } 7-\mathrm{d}\end{array}$ & $\begin{array}{l}3 \mathrm{~h} \text { before } \\
\text { test }\end{array}$ & Distance covered during a repeated sprint test to fatigue ( $4 \mathrm{~km})$ \\
\hline $\begin{array}{l}\text { Perkins, } 2019 \\
\text { [22] }\end{array}$ & $\begin{array}{l}16 \text { males (active); } \\
\text { crossover }\end{array}$ & $\begin{array}{l}210 \mathrm{mg}^{-1} \mathrm{~d}^{-1} \mathrm{BC} \\
\text { anthocyanins for } 7-\mathrm{d}\end{array}$ & $\begin{array}{l}\text { Not } \\
\text { reported }\end{array}$ & $\begin{array}{l}\text { Distance covered during a repeated sprint test to fatigue (4.7 } \\
\mathrm{km})\end{array}$ \\
\hline $\begin{array}{l}\text { Potter, } 2020 \\
{[23]}\end{array}$ & $\begin{array}{l}18 \text { males, } 2 \text { females } \\
\text { (active); crossover }\end{array}$ & $\begin{array}{l}210 \mathrm{mg}^{-1} \mathrm{~d}^{-1} \mathrm{BC} \\
\text { anthocyanins for } 7-\mathrm{d}\end{array}$ & $\begin{array}{l}\text { Not } \\
\text { reported }\end{array}$ & $\begin{array}{l}\text { Hang time during a simulated rock climbing test to fatigue (30 } \\
\text { s) }\end{array}$ \\
\hline $\begin{array}{l}\text { Willems, } 2015 \\
\text { [24] }\end{array}$ & $\begin{array}{l}8 \text { males, } 5 \text { females } \\
\text { (active); crossover }\end{array}$ & $\begin{array}{l}138.6 \mathrm{mg} \cdot \mathrm{d}^{-1} \mathrm{BC} \\
\text { anthocyanins for } 7-\mathrm{d}\end{array}$ & $\begin{array}{l}2-3 \mathrm{~h} \\
\text { before test }\end{array}$ & Power output at set lactate level during a cycle test (225 watts) \\
\hline $\begin{array}{l}\text { Willems, } 2016 \\
{[14]}\end{array}$ & $\begin{array}{l}13 \text { males (active); } \\
\text { crossover }\end{array}$ & $\begin{array}{l}105 \mathrm{mg}^{-1} \mathrm{~d}^{-1} \mathrm{BC} \\
\text { anthocyanins for } 7-\mathrm{d}\end{array}$ & $\begin{array}{l}3 \mathrm{~h} \text { before } \\
\text { test }\end{array}$ & $\begin{array}{l}\text { Run time during a run test to fatigue following a sprint test (14 } \\
\text { min) }\end{array}$ \\
\hline
\end{tabular}

Key: ${ }^{\mathrm{a}} B C=$ Blackcurrant 
Table 2 Details of blackcurrant studies included which report oxidative, inflammatory, and cognitive outcomes

\begin{tabular}{|c|c|c|c|c|}
\hline Study & Subjects; design & BC anthocyanin dose $\mathrm{e}^{\mathbf{a}}$ & Final dose & Outcomes measures $^{\mathbf{b}}$ \\
\hline $\begin{array}{l}\text { Hurst, } 2019 \\
{[25]}\end{array}$ & $\begin{array}{l}32 \text { males and females; } \\
\text { parallel design }\end{array}$ & $\begin{array}{l}\text { 0.8, 1.6, or } 3.2 \mathrm{mg} \cdot \mathrm{kg}^{-1} \text { body weight BC extract } \\
\text { (34\% anthocyanins) ( } 8 \text { individuals per group). } \\
\sim ~ 20,40 \text { and } 80 \mathrm{mg} \text { BC anthocyanins consumed } \\
\text { acutely }\end{array}$ & $\begin{array}{l}1 \mathrm{~h} \text { before } \\
\text { test }\end{array}$ & $\begin{array}{l}\text { Oxidative measures } \\
\text { (FRAP, PC) }\end{array}$ \\
\hline $\begin{array}{l}\text { Hurst, } 2019 \\
{[26]}\end{array}$ & $\begin{array}{l}20 \text { males and females; } \\
\text { parallel design }\end{array}$ & $\begin{array}{l}3.2 \mathrm{mg} \cdot \mathrm{kg}^{-1} \text { body weight } \mathrm{BC} \text { extract } \\
\text { (34\% anthocyanins). } \mathrm{d}^{-1} \text { for } 5 \text {-wk. } \\
\sim 80 \mathrm{mg} \mathrm{BC} \\
\text { anthocyanins daily. }\end{array}$ & $\begin{array}{l}2 \mathrm{~h} \text { before } \\
\text { test }\end{array}$ & $\begin{array}{l}\text { Oxidative measures } \\
\text { (MDA, FRAP, IL-6, IL-10, TNFa) }\end{array}$ \\
\hline $\begin{array}{l}\text { Lomiwes, } \\
2019[27]\end{array}$ & $\begin{array}{l}15 \text { males and } 25 \text { females; } \\
\text { parallel design }\end{array}$ & $\begin{array}{l}4.8 \mathrm{mg} \cdot \mathrm{kg}^{-1} \text { body weight BC concentrate } \\
\text { diluted in water }(200 \mathrm{~mL}) \text { prepared and } \\
\text { onsumed acutely. } \sim 120 \mathrm{mg} \mathrm{BC} \text { anthocyanins. }\end{array}$ & $\begin{array}{l}1 \mathrm{~h} \text { before } \\
\text { test }\end{array}$ & $\begin{array}{l}\text { Cognitive measures (MAO-B). } \\
\text { Oxidative measures (MDA) }\end{array}$ \\
\hline $\begin{array}{l}\text { Lyall, } 2009 \\
\text { [2] }\end{array}$ & $\begin{array}{l}5 \text { males and } 5 \text { females; } \\
\text { crossover }\end{array}$ & 240 mg BC anthocyanins consumed acutely & $\begin{array}{l}\text { 30-min } \\
\text { before test }\end{array}$ & Oxidative measures (PC), Side effects \\
\hline $\begin{array}{l}\text { McGhie, } \\
2007[1]\end{array}$ & $\begin{array}{l}20 \text { male and female older } \\
\text { adults in control and } \\
\text { blackcurrant arm; parallel design }\end{array}$ & $\begin{array}{l}500 \mathrm{mg} \text { BC anthocyanins daily for } 24 \text { weeks } \\
\text { from BC extract and concentrate diluted in } \\
\text { water ( } 200 \mathrm{~mL} \text { ) }\end{array}$ & $\begin{array}{l}\text { Not } \\
\text { reported }\end{array}$ & Oxidative measures (PC, MDA) \\
\hline $\begin{array}{l}\text { Watson, } \\
2015[28]\end{array}$ & $\begin{array}{l}36 \text { males and females, 3-arm; } \\
\text { crossover }\end{array}$ & $\begin{array}{l}\sim 500 \mathrm{mg} .60 \mathrm{~kg}^{-1} \text { body weight BC anthocyanins } \\
\text { extract; OR } \sim 400 \mathrm{mg} .60 \mathrm{~kg}^{-1} \text { body weight } \\
\text { BC anthocyanins juice, consumed acutely }\end{array}$ & $\begin{array}{l}1 \mathrm{~h} \text { before } \\
\text { test }\end{array}$ & $\begin{array}{l}\text { Cognitive measures (MAO-B, Stroop } \\
\text { test, Digit Divigilance test) }\end{array}$ \\
\hline $\begin{array}{l}\text { Watson, } \\
2018[29]\end{array}$ & 8 males; crossover & $\begin{array}{l}\sim 6.2 \text { mg. } \mathrm{kg}^{-1} \text { body weight } B C \text { anthocyanins } \\
\text { juice, consumed acutely }\end{array}$ & $\begin{array}{l}\text { Not } \\
\text { reported }\end{array}$ & Cognitive measures (MAO-B) \\
\hline
\end{tabular}

Key: $a \mathrm{BC}=$ Blackcurrant; $\mathrm{b}$ FRAP=Ferric reducing ability of plasma, $\mathrm{PC}=$ Protein carbonyl, MDA = Malondialdehyde, MAO-B=Platelet monoamine oxidase-B activity

"bad." However, it has been identified that oxidative stress can initiate signaling to support improved training adaptations and nutrients with very high antioxidant capacity may not be in the best interest of the athlete if taken chronically [32]. In the analysis, we attempted to define whether NZ BC altered the oxidative or inflammatory response to exercise and failed to see a consistent response outside the inherent variability of the biomarkers (demonstrated as the factor standard deviation presented in the results to support Fig. 3). However, of significant interest are the studies including an acute and chronic component, clearly showing an increase in inflammatory markers (TNF $\alpha$, IL-6, IL-10) and an oxidative stress marker (FRAP) while ingesting NZ $\mathrm{BC}$ prior to exercise, but not after. It is possible the NZ $\mathrm{BC}$ is priming the antioxidant and inflammatory responses. NZ BC anthocyanins appear to interact with cellular antioxidant systems and mediate enhancement of antioxidant defenses and mitochondrial adaptation which are likely to be far more important than the oxidative scavenging activity [33]. Oxidative stressors that are proposed to induce mitochondrial adaptation include exercise, calorie restriction, and polyphenols acting as pro-oxidant primers [34]. The central signaling molecule likely to be important in these adaptive responses is nuclear factor (erythroid-derived 2)-like 2, also known as Nrf-2 [25]. Nrf-2 is a transcription factor and is regarded as a master regulator of antioxidant, inflammatory and mitochondrial responses. The Nrf family activate genes that encode mitochondrial respiratory chain and translocation proteins [35]. Under normal homeostatic conditions, $\mathrm{Nrf}-2$ is suppressed and becomes active upon exposure to oxidative stress whereby it translocates into the nucleus and binds to the antioxidant response element of the genes of antioxidant enzymes. This results in the initiation of the transcription of the genes that control adaptive enzymes which in turn manage the oxidative stress $[25,33]$. While the data we extracted in this review failed to see a difference in oxidative markers when taking NZ BC compared with control, we do acknowledge the number of studies included was very low, too low to meta-analyse or make meaningful conclusions. However, in theory, the provision of a moderate dose of $\mathrm{BC}$ anthocyanins may be priming the antioxidant and inflammatory processes, while activating mitochondrial growth to support peak performance.

The oxidative and inflammatory outcome measures included in this review are widely studied, but it should be acknowledged that more sophisticated measures may better differentiate changes with dietary intervention. Modern approaches include in vitro assays, metabolic and microRNA approaches, which require more research before results can be used to guide evidence-based practice. One of the limitations of the current review is the reliance on relatively crude oxidative and inflammatory markers which may in part explain the lack of clarity in the oxidative outcome measures.

Aside from the performance response, the cognitive and mood attributes appear trivial, with improvements in cognitive test score and monoamine oxidase (MAO) inhibitory effects thought to enhance cognition and mood [27, 28]. Studies have reported monoamine 
oxidase enzyme inhibition in humans after taking blackcurrant which may maintain neurotransmitter function, leading to improvements in cognition and mood [27, 28], and as such is a biomarker of cognition. Cognitive effects of polyphenols may result from the vasodilator activity which aligns with the short time frame of action [28]. Our results did not support a cognitive improvement.

To our knowledge, no single study has investigated nutrient supplementation and timing over a competitive season, let alone investigated the personalised approach of NZ BC. Certainly for athletes competing multiple times in a year, thought should be given to an ideal, personalised, supplement regime.

\section{Conclusions}

New Zealand grown blackcurrants mediate a small, significant improvement on athletic performance, particularly when consumed for 7 days at a dose of $105-210 \mathrm{mg}$ anthocyanins, with a final dose $1-2 \mathrm{~h}$ before exercise. The predominant form of NZ BC used in studies was powdered product in capsules. While the evidence for a direct effect on sport performance was clear, the mechanism is not. We found only a small number of studies that have investigated oxidative, cognitive and adverse outcomes, with no known detrimental side effects reported.

\section{Supplementary information}

Supplementary information accompanies this paper at https://doi.org/10. 1186/s12970-020-00354-9.

Additional file 1. Medline Search Strategy.

\section{Abbreviations}

NZ BC: New Zealand blackcurrant; PC: Protein carbonyl;

MDA: Malondialdehyde; FRAP: Ferric reducing ability of plasma; IL-

1: interleukin-1; IL-8: Interleukin-8; IL-10: Interleukin-10; IL-6: Interleukin-6; TNF

a: Tumour necrosis factor-alpha; MAO: Monoamine oxidase activity/

concentration

\section{Acknowledgements}

Nil

\section{Authors' contributions}

$A B$ and $\mathrm{RH}$ designed the investigation, $\mathrm{VS}$ and $A B$ ran the search, extracted data and analysed data, AB, VS and RH wrote the manuscript. The author(s) read and approved the final manuscript

\section{Funding}

Funding was received from government-owned Crown research institute (The New Zealand Institute for Plant and Food Research) to complete this investigation.

\section{Availability of data and materials}

Data used in this review have been sourced from available data and can be shared by contacting the primary author. The search strategy is available as supplementary information.

\section{Ethics approval and consent to participate}

The data used in the current manuscript was derived from previously published and/or presented research. Ethical approval is not required for reanalysis of data that has received ethical approval.

\section{Consent for publication}

No individual data or image has been used in the manuscript.

\section{Competing interests}

All authors are associated with academic or government institutions, with no competing interests. The results are presented clearly, honestly, without

fabrication, falsification, or inappropriate data manipulation.

\section{Author details}

${ }^{1}$ Discipline of Nutrition, Faculty of Medical \& Health Sciences, The University of Auckland, Private Bag, Auckland 92019, New Zealand. ${ }^{2}$ The New Zealand Institute for Plant and Food Research Limited, Food Innovation Portfolio,

Food \& Wellness Group, Private Bag, Palmerston North 11600, New Zealand.

Received: 5 February 2020 Accepted: 30 April 2020

Published online: 27 May 2020

\section{References}

1. McGhie TK, Walton MC, Barnett LE, et al. Boysenberry and blackcurrant drinks increased the plasma antioxidant capacity in an elderly population but had little effect on other markers of oxidative stress. J Sci Food Agric. 2007;87(13):2519-27. https://doi.org/10.1002/jsfa.3019.

2. Lyall KA, Hurst SM, Cooney J, et al. Short-term blackcurrant extract consumption modulates exercise-induced oxidative stress and lipopolysaccharide-stimulated inflammatory responses. Am J Phys Regul Integr Comp Phys. 2009;29(1):70-81. https://doi.org/10.1152/ajpregu.90740 2008.

3. Cook MD, Willems MET. Dietary anthocyanins: a review of the exercise performance effects and related physiological responses. Int J Sport Nutr Exerc Metab. 2019:29(3):322-30.

4. Maughan RJ, Burke LM, Dvorak J, et al. IOC consensus statement: dietary supplements and the high-performance athlete. Int J Sport Nutr Exerc Metab. 2018;28(2):104-25. https://doi.org/10.1123/ijsnem.2018-0020.

5. Somerville $V$, Bringans $C$, Braakhuis AJ. Polyphenols and performance: a systematic review and meta-analysis. Sports Med. 2017;47(8):1589-99. https://doi.org/10.1007/s40279-017-0675-5.

6. De Pascual-Teresa S, Moreno DA, García-Viguera C. Flavanols and Anthocyanins in cardiovascular health: a review of current evidence. Int J Mol Sci. 2010;11(4):1679-703

7. Kader F, Rovel B, Girardin M, Metche M. Fractionation and identification of the phenolic compounds of Highbush blueberries (Vaccinium corymbosum L.). Food Chem. 1996;55(1):35-40. https://doi.org/10.1016/03088146(95)00068-2

8. Tang $X$, Shen $T$, Jiang $X$, et al. Purified Anthocyanins from bilberry and black currant attenuate hepatic mitochondrial dysfunction and Steatohepatitis in mice with methionine and choline deficiency. J Agric Food Chem. 2015; 63(2):552-61. https://doi.org/10.1021/jf504926n.

9. Liobikas J, Skemiene K, Trumbeckaite S, et al. Anthocyanins in cardioprotection: a path through mitochondria. Pharmacol Res. 2016;113: 808-15. https://doi.org/10.1016/j.phrs.2016.03.036.

10. Huang W-Y, Liu Y-M, Wang J, et al. Anti-inflammatory effect of the blueberry Anthocyanins Malvidin-3-Glucoside and Malvidin-3-Galactoside in endothelial cells. Molecules. 2014;19(8):12827-41

11. Schrage B, Stevenson D, Wells RW, et al. Evaluating the health benefits of fruits for physical fitness: a research platform. J Berry Res. 2010;1 (1):35-44.

12. Higgins JPT, Altman DG, Gøtzsche PC, et al. The Cochrane Collaboration's tool for assessing risk of bias in randomised trials. BMJ. 2011;343:d5928. https://doi.org/10.1136/bmj.d5928.

13. Willems ME, Myers SD, Blacker SD, et al. CurraNZ blackcurrant improves cycling performance and recovery in trained endurance athletes. J Int Soc Sports Nutr. 2014;11(1):P14. https://doi.org/10.1186/1550-2783-11-s1-p14.

14. Willems M, Cousins L, Williams D, et al. Beneficial effects of New Zealand blackcurrant extract on maximal sprint speed during the Loughborough intermittent shuttle test. Sports. 2016;4(3):42.

15. Rhodes K, Braakhuis A. Performance and side effects of supplementation with N-Acetylcysteine: a systematic review and meta-analysis. Sports Med. 2017:47(8):1619-36. https://doi.org/10.1007/s40279-017-0677-3.

16. Braakhuis AJ, Hopkins WG, Lowe TE. Effects of dietary antioxidants on training and performance in female runners. Eur J Sport Sci. 2014:14(2):1608. 
17. Borenstein M, Hedges LV, Higgins JPT, et al. A basic introduction to fixedeffect and random-effects models for meta-analysis. Res Synth Methods. 2010;1(2):97-111. https://doi.org/10.1002/jrsm.12.

18. Cook MD, Myers SD, Blacker SD, et al. New Zealand blackcurrant extract improves cycling performance and fat oxidation in cyclists. Eur J Appl Physiol. 2015;115(11):2357-65.

19. Godwin C, Cook MD, Willems MET. Effect of New Zealand blackcurrant extract on performance during the running based anaerobic Sprint test in trained youth and recreationally active male football players. Sports. 2017; 5(3):69.

20. Murphy C, Cook M, Willems M. Effect of New Zealand blackcurrant extract on repeated cycling time trial performance. Sports. 2017;5(2):25.

21. Perkins IC, Vine SA, Blacker SD, et al. New Zealand blackcurrant extract improves high-intensity intermittent running. Int J Sport Nutr Exerc Metab. 2015:25(5):487-93.

22. Perkins IC, Blacker SD, Willems MED. Intra-individual responses to New Zealand blackcurrant extract during high-intensity, intermittent running: a repeat response study. Conference poster. Int J Sport Nutr Exerc Metab. 2019;29(Suppl1):S1-S16. https://doi.org/10.1123/ijsnem.2019-0057.

23. Potter JA, Hodgson Cl, Broadhurst M, Howell L, Gilbert J, Willems ME, Perkins IC. Effects of New Zealand blackcurrant extract on sport climbing performance. In: European College of Sports Science, 4-7 July 2018, Dublin, Republic of Ireland.

24. Willems MET, Myers SD, Gault ML, et al. Beneficial physiological effects with blackcurrant intake in endurance athletes. Int I Sport Nutr Exerc Metab. 2015;25(4):367-74.

25. Hurst RD, Lyall KA, Roberts JM, et al. Consumption of an Anthocyanin-Rich Extract Made From New Zealand Blackcurrants Prior to Exercise May Assist Recovery From Oxidative Stress and Maintains Circulating Neutrophil Function: A Pilot Study. Front Nutr. 2019;6(73). https://doi.org/10.3389/fnut. 2019.00073.

26. Hurst RD, Lyall, KA, Wells, RW, et al. Daily consumption of Rakoha'm anthocyanin-rich extract made from New Zealand blackcurrants for 5 weeks supports exercise recovery through the management of oxidative stress and inflammation. 2019. Unpublished Data.

27. Lomiwes D, Ha B, Ngametua N, et al. Timed consumption of a New Zealand blackcurrant juice support positive affective responses during a selfmotivated moderate walking exercise in healthy sedentary adults. J Int Soc Sports Nutr. 2019;16(1):1-4

28. Watson AW, Haskell-Ramsay CF, Kennedy DO, et al. Acute supplementation with blackcurrant extracts modulates cognitive functioning and inhibits monoamine oxidase-B in healthy young adults. J Funct Foods. 2015;17:52439. https://doi.org/10.1016/j.jf.2015.06.005.

29. Watson AW, Scheepens A, Kennedy DO, et al. The pharmacodynamic profile of "Blackadder" blackcurrant juice effects upon the monoamine axis in humans: a randomised controlled trial. Nutr Neurosci. 2018:1-10. https://doi. org/10.1080/1028415X.2018.1525950.

30. Christensen PM, Shirai Y, Ritz C, Nordsborg NB. Caffeine and Bicarbonate for Speed. A Meta-Analysis of Legal Supplements Potential for Improving Intense Endurance Exercise Performance. Front Physiol. 2017;8(240). https:// doi.org/10.3389/fphys.2017.00240

31. Chen L, Cao H, Xiao J. Polyphenols: Absorption, bioavailability, and metabolomics. In: Polyphenols: Properties, Recovery, and Applications. Beijing: Woodhead Publishing. Elsevier; 2018. p. 45-67.

32. Merry $T L$, Ristow M. Do antioxidant supplements interfere with skeletal muscle adaptation to exercise training? J Physiol. 2016;594(18):5135-47.

33. Hurst SM, Hurst RD. Anthocyanins, Innate Immunity, and Exercise. In Anthocyanins in Health and Disease. Melbourne: CRC Press. Taylor \& Francis Books (Australasia); 2013. p. 338-53.

34. Stevenson DE. Polyphenols as Adaptogens-The Real Mechanism of the Antioxidant Effect? In: Rasooli I, editor. Bioactive Compounds in Phytomedicine. Germany: Intech Open, BoD - Books on Demand; 2012. p. 143-62.

35. Hawley JA, Holloszy JO. Exercise: it's the real thing! Nutr Rev. 2009;67(3):1728. https://doi.org/10.1111/j.1753-4887.2009.00185x.

\section{Publisher's Note}

Springer Nature remains neutral with regard to jurisdictional claims in published maps and institutional affiliations.

\section{Ready to submit your research? Choose BMC and benefit from:}

- fast, convenient online submission

- thorough peer review by experienced researchers in your field

- rapid publication on acceptance

- support for research data, including large and complex data types

- gold Open Access which fosters wider collaboration and increased citations

- maximum visibility for your research: over $100 \mathrm{M}$ website views per year

At BMC, research is always in progress.

Learn more biomedcentral.com/submissions 